\title{
The Dharma of Ecology - Contemporary Narratives of Environmental Politics
}

\author{
Ragini Kapoor \\ PhD Fellow, Comparative Indian Literature, Department of Modern Indian Languages and Literary Studies, \\ University of Delhi, Delhi, India
}

\begin{abstract}
What could be the reason that as twenty-first century beings, humanity still fails to save the planet Earth, its natural sources, and all its species, most of them on the verge of getting extinct! Environmental Politics certainly needs to take the charge to pinch the much-needed wake-up call for all. Dharma, or simply put, one's duty, embraces a lot of profound principles to live a contented life, foremost for others, and lastly, for oneself. Dharma of Ecology means that though nature's duty is to nourish everyone but then it has been made to compromise in front of humanity's egoistic aims. And it also stands what should be one's dharma to save ecology or nature as such. Taking nature's beauty and might for granted will let nature reduced to a term, "cultural discourse". In fact, nature will ever remain as undefined. Not everything needs a definition especially when something prevails as a nurturer of all. Ecological thinking requires nature to be given a voice for unfortunately humanity seems to ignore the wondrous and everlasting existence of nature as a whole. If all things natural have been made to compromise then the change and the solutions have to come from humanity itself. This is something which is simple to understand but difficult to implement still. The paper tries to fulfil the objective of explaining these terse and laconic statements that highlight the twenty-first century.
\end{abstract}

Key words: Dharma, Ecological Peace, Moral Renaissance, Peace Building, Environmental Politics

Purpose/Objective: The paper aims to examine the dharma of ecology per se in understanding ecology and contemporary environmental politics which are strong catalysts for sustenance of dharma and nature for all. Ecology has a deep interconnection with dharma, and both being moral issues require all consideration for the peaceful existence and survival of human beings along with other living creatures and non living materials. And for that a renaissance of values to bring necessary changes in societies around the world has to take place to rescue nations and, thus, the entire world, and put them on the path of global peace and harmony.

\section{Methodology/Approach:}

1) The discourses on nature would be concerning themselves with the decisive matter of the relationship between humans beings, cultures of all, and ecology, firmly believing that ecology affects human life irreversibly. Hence, a nature-centred approach has been followed to write the paper.

2) This paper is based on the methods of Analytical Research segment, implying to consider the data already available in the form of environmental narratives, thereby to analyse the data to make a critical evaluation to reach out to anticipated outcomes. 


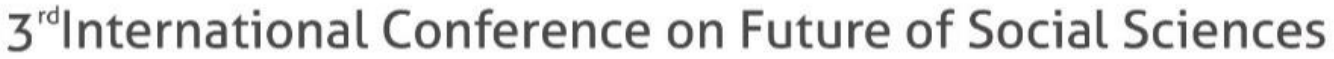

3) As also belonging to segments of Fundamental Research, Qualitative Research, and Conceptual Research, this paper will concern itself to framing the twenty-first century narratives on environmental politics.

Findings/Results: Taking cues from classical Indian canon, Vedas and Upanishads, which teach principles of dharma, this paper also leads to the coinage of a term Eco-Indo Aesthetics which shall aim to explain how Ecological Aesthetics are influenced by Indian Aesthetics, a notion that has not been focused upon well in the contemporary times, thereby proving that the principles of dharma influence green narratives of ecology for good.

Conclusion: It is important to understand that dharma and ecology are interconnected. And for that, understanding environmental narratives in ancient scriptures is the need of the hour. That the discourses around their interconnectedness may be termed as "spiritual", but the paper also tries to conclude inevitably that environmental politics should not revolve around polarised ideologies but must positively influence one and all around the globe, for the Sanskrit adage, vasudev kutumbakam (world is a one big family), is still held true.

\section{References:}

1) An environmental science book by Rachel Carson - Silent Spring, published 1962.

2) The Environmental Imagination by Lawrence Buell, published: 1995.

3) Vedas and Upanishads (translated to English and Hindi)

4) Nature and Human Nature by Murali Sivaramakrishnan, published: 2008.

5) Mind and Nature: A Necessary Unity by Gregory Bateson, published: 1980.

6) Ecological Criticism for Our Times: Literature, Nature and Critical Inquiry by Murali Sivaramakrishnan and Ujjwal Jana, published: 2011.

7) The Green Machines by Nigel Calder, published: 1986.

8) Ecoambiguity, Community and Development: Toward a Politicized Ecocriticism edited by Scott Slovic, Swarnalatha Rangarajan, and Vidya Sarveswaran, published 2014.

The narratives of dharma and ecology do not stand independently anymore. The discourses on religion and peace that may be interrelated (/not) are rooted in the past of India's heritage. Dharma and ecology, as two ever-widening concepts, are interrelated philosophically and spiritually, through that understanding one may get to consider the inner crises of the mind and the spirit which are ultimately becoming the deciding clauses for the welfare of ecology and biosphere. Human ties with nature were deeply felt in ancient times and the idea on ecological balance of a place is revealed and explicated by its flora, fauna and water elements. The policies for the protection of the environment and sustenance of ecological balance had in themselves the core element of dharma, the right behaviour by a common man. The awareness of such policies has been ensuring survival of all and various cultures and sustained practices. Unchanged practices definitely get lives and cultures in danger, and pose multiple threats as can be seen in the contemporary times. The world is ridden with ecological and environmental catastrophe may be due to the actions of humanity. Survival chiefly depends on dharma, the certain and postulated Indian experience, which is a test for contemporary existence of all and their morality.

Dharma of ecology is to understand ecology which is a strong catalyst for sustenance of dharma itself. There is an abundance of both natural and human resources, in fact, human resources get multiplied with every passing moment, but there is no cautious preservation of 


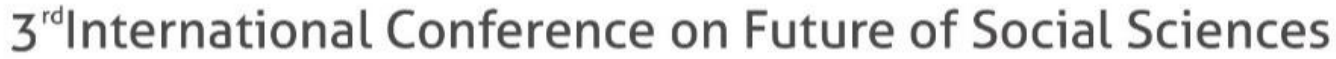

them. And it is important to make sure that material progress, if remains unchecked, will not bring satisfactory cheers in one's life, for it has to blend in spiritual values to make material development meaningful for a person and for his or her society as well. In this moment, dharma is vitally needed to keep a check on national crisis which involves moral decay and decline of one's character in his or her society which ultimately leads to poisoning of the spirits of all nations. India is going through such a crisis for now and the pace of this decay and its spread is unquestionable, and to safeguard India's integrity this moral decay has to be checked and stemmed. Therefore, a renaissance of values in society has to take place. It depends on the most intelligent species how this renaissance comes about and what shall its instrument be, and that on what ideology one may have to give his or her commitment to implement a positive agenda for this renaissance. To understand the dharma of ecology and to implement its principle(/s) is the need of the hour.

Nature is an old, difficult, certain, and now a progressive concept, and ecology is a science that would matter for eternity. The concept of dharma has permeated all faces and facets of Indian tradition to this day, it was a simple concept in the Vedic Period, it gradually transcended the complexities of myriad ideologies that exist today. Dharma inclines to the cosmic rhythm and since the Vedic Age it has taught one to stay rooted to nature to exist with contentment. This cosmic rhythm permeates and sustains the world around and the whole universe. A philosophical understanding of ecology and its facets is also important for a number of reasons. Firstly, though it is a branch of biology, but it has distinctive philosophical issues. Secondly, ecology is a step away from dire political and ethical decisions about management about how best to live in an apparently degraded environment. Thirdly, philosophy of ecology can contribute to an understanding of ecology and to its advancement that would result in its advancement as an organic concept. There is an excruciating pressure over ecologists and environmentalists to sort out a defensive position for the world. Dharma is one of the most valuable contributions of India to humanity. As one of the key concepts in Indian thought, it still has its great relevance in contemporary age. It has acquired various senses in the long history of India's spiritual and cultural development. Dharma prevails almost all the philosophical systems of India. Dharma may be understood differently according to these various philosophical systems but it generally means the duty of a man and his moral pursuit to live his life.

The Dharma of Ecology could imbibe the following considerations - the well-being and flourishing of human and non-human life on earth. They are interconnected but not interdependent as such. It is now become essential to retain the diversity and richness of all life forms. Humans certainly have no exclusive right to trouble this balance and reduce this richness and diversity to satisfy their temporary madness of contentment. The increase in human population is contributing massively in substantial decrease in the flourishing of human life and various cultures. However, human beings' interference in with the natural world is excessive, the effects of which have now become irreversible. The situation is merely worsening and policies must therefore be changed to concentrate on progress of economical, ideological, and technological structures. Ideological change lies at the base which is that of appreciating ecology and life quality rather than restricting to mere higher standard of living. Here comes the principle of dharma to uplift the spirits of one and all. That which assures welfare of all living beings and their peace, is, for sure, dharma. The dharma of ecology as a contemporary concept has to be considered seriously in the twenty-first century. It highlights the current and gradually developing narratives on ecological peace. It focuses on a relationship which human beings and other living beings on earth share with nature. That 


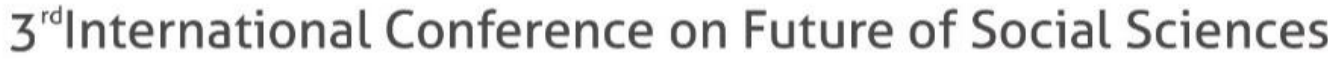

relationship shall be maintained by the selfless care of nature by human beings without analysing their ultimate reliance on nature for the survival of all. Since his evolution, man has been relying on his surroundings and the natural forces which encompass flora and fauna. Sorted agricultural reforms and civilisations strengthened his relationship with ecology, realising that he can modify and control these forces of nature. However it is important to understand the concepts of environment ecology or ecosystems. Time and space must be carefully considered when describing an ecological phenomena. In reference to time, it can take thousands of years for ecological processes to positively mature and strengthen themselves. A scientific insight that involves only human-centred approach is a misguided and negative way to comprehend things. An eccentric attitude may be appreciated but that does not have to be dominating and aggressive towards nature. One has to feel identified with nature and surroundings around via neglecting personal egos and degrading attitudes. That involves a radical and consistent change of consciousness to protect nature. Deep Ecology is the spiritual dimension of the environmental movement. It is a holistic approach to face problems related to ecosphere which brings together the valuables - thinking, feeling, spirituality, and action. It involves moving beyond the individualism and materialism of Western civilisation to have a look at human beings along with other living beings as part of the earth to come full circle. This leads to a deeper connection with all life, not just seen as something out there in the world, but something everyone is a part of and has a role to play in to save nature.

A government that relies on its principles of liberty and justice, manages to survive on a high moral ground. Justice that does not focus on social justice has no significance. Social justice has been the base of major social and political reform movements throughout the history. Here is where the concept of ecology coincides to protecting the nature and retaining the principles of justice that underline one's walk on the path of dharma to prevent moral and physical decay of human spirits and consciences. Diversity and complexity are major concerns here. Symbiosis is the most important condition to maximise diversity. No life is lesser than the other. Truly ecological thinking may not be compatible with today's narratives but to maintain multifaceted quality a lot of conventional discourses have to run in the forefront as a mentor for all lives to follow. The dharma of ecology involves to confront the great philosophical problems of man, that may seem unreal but exist as rebellious transience, meaning, and limitation - without fear. Affirmation of its own organic essence will be the ultimate test of the human mind and of its subjective act of judging.

One cannot be an environmental activist/an advocate without paying heed to interdependence of the movements. Ecology as a scientific discipline points towards a fundamental interconnectedness of all species as well as all non-living processes. No species plays one mere role to maintaining the ecosystem. Roles played by all species are interdependent to maintain the existence of all communities. But how does this matter to define eco-dharma? Meditating in a natural environment will certainly help all environmental activists to retain their activism, which would lead them to go beyond self-righteousness to realise sheer compassion for all and for themselves, too. Dharma has to be applied in the societal and institutional issues rather than just in one's individual or family life. "Eco" in eco-dharma is not just about environment or nature or what is defined as wilderness. It is about the survival of the planet earth as a whole to maintain the sacred bond between all living beings and ecosphere. True eco-dharma communities are needed now to look at the psycho-spiritual causes, and the institutional causes of ecological sustenance. 


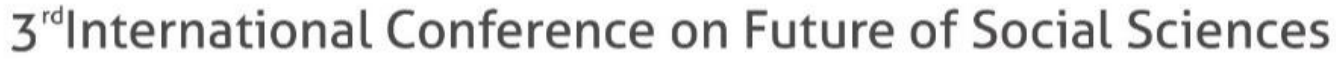

Environment does not exist in isolation and it cannot heal in isolation. Human beings need to collectively revisit how to define nature, that how it originally existed sans human beings, and how wilderness was created in the world. It is needed to develop interdependent communities that focus on this simple narrative that different people have different privileges and abilities. The privileged ones need to actively include and understand voices that have been historically oppressed. It is needed to question and discard the economic and financial systems that no longer serve the planet. Unless the framework of eco-dharma in contemporary times acknowledges and includes all these inter-connections, eco-dharma will just become a mere environmental movement getting dragged with no substantial aims in the twenty-first century.

Nature is overwhelming in all aspects fathomed. It is the sublime bond shared by the human beings with ecology that makes this interpenetrative bond special. This sublime bond considers the reverence paid to ecology by human beings by worshipping it and consciously accepting its overwhelming power to protect all living beings. It is important for one and all to roll back to the classical written works to get acquainted with this aspect of importance of nature and how its beauty would never fade. Questions may be raised while studying aesthetics of ecology and how literature plays an important part - Can literature be examined as having some bearing on man and his relation to the ecosphere? And: Can literature should literature - serve as an agency of awareness or acquaintance? Should it be publicised to help advance the cause of protection of natural environment? All these questions may be answered once the development of the idea is fulfilled as how nature shares its role with human beings and vice versa. The power of nature is the most overwhelming force. The notion of power need not be considered only as a destructive force for that is one way to understanding nature's power. Juxtaposition of nature's enchantment (owing to its beauty) and its power also implies the way all the creatures get significantly blessed by nature's presents which it bestows on them all. This power of bestowment allows for a "Through the Looking Glass" interpretation of nature as well. The relationship that nature shares with human beings need not signify only the mirror image of reality but a covert interpretation as well that nature also is responsible for spiritual growth of all creatures which is capable of great transformations. In the twenty-first century, it has become a major concern for us all to save ecology and the aim is to consider rethinking of the notion that though our natural surroundings have to be saved, literature, too, indeed plays an important role in bringing this concern forward.

Indian Aesthetics is understood in terms of systems and symbols that are creative and openminded. They embody "open-space" visions. Its principles transcend cultural boundaries that are essential to understand Ecological Aesthetics. Thereby, the term Eco-Indo Aesthetics comes to the fore which combines both Indian Aesthetics and Ecological Aesthetics to appreciate nature and its yet-to-be-comprehended rules. This expands the scope of environmental aesthetics, which twenty-first century indeed requires for its intense and renewed investigations. It is the lack of aesthetics values that have not been imbibed in political agendas of today to, in simple terms, save nature for good. Eco-Indo Aesthetics will change the point of views that people today hold that a mere commercialised and urbanised world will not be at the receiving end, and that leaders of twenty-first century must promote ecologically oriented conservation policies which shall remain unchallenged in the long run. "Nature" or the physical environment is a realist concept which refers to the laws of the physical world. Those laws are well-delineated in the classical Indian canon, Vedas and 


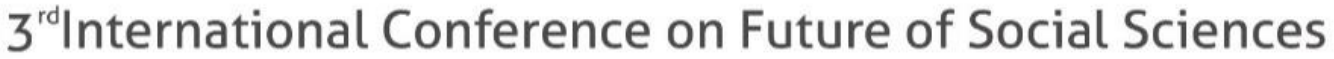

\section{5 - 7 March 2021}

Upanishads, whose teachings have granted all the respect to the nurturing nature appreciating the five elements which make all human beings, viz. earth, water, fire, air, and space. It is the dharma of every human being to preserve and nurture these elements for conservation of nature and development of all beings. So stands this as the principle of Eco-Indo Aesthetics to know nature as it should be known, as the mysterious force without whose existence there stands nothing.

It is thus important to understand the essence of the dharma of ecology as a discipline - its perception of the world as evolutionary ecosystem in which lines of connection and interdependence extend in all directions. By continuously adapting to each other, the different creatures and substances are reshaping and developing each other, and the physical world they inhabit. It is important to combine ecological insights with those of poststructuralism which takes into account human affairs and their cultures. The ecological thought is a thought about ecology, but the thinking is also ecological. Traditionally, it is the all-encompassing metaphorical figure for ecological interconnection, which also includes artificial things. Nature is a mesh of all things. An ecological approach may be guided by the principle of looking for interconnections, and by the related ecological concept of the "niche": to make it possible for a species to survive in any ecosystem. The search remains for interconnections, but also for barriers that keep things apart, considering the incompatible forces. The most important example of this co-existence will be the way environmental values and concerns can be comprehended and professed and felt deeply by people and politicians who express belief in the dangers of global warming but do not take necessary actions they are expected to take. That is how the contemporary narratives of ecological peace are shaped, to take action considering what has been said and followed. Ecology has a deep interconnection with dharma, and both being moral issues require all consideration for the peaceful existence and survival of human beings along with other living creatures and non living materials. And for that a renaissance of values in societies and cultures around the world has to take place to rescue nations and put them on the path of global peace and harmony. 


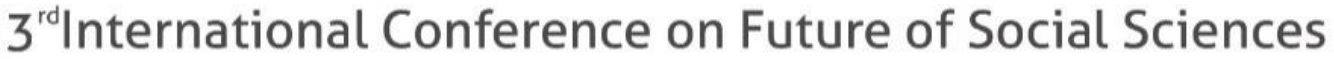

\section{Bibliography}

Borlik, Todd A. Ecocriticism and Early Modern English Literature. Abingdon (The UK): Routledge. 2011.

Glotfelty, Cheryll and Harold Fromm. The Ecocriticism Reader: Landmarks in Literary Ecology. Georgia (The USA): University of Georgia Press. 1996.

Hiltner, Ken (ed.). Ecocriticism: The Essential Reader. Abingdon (The UK): Routledge. 2015.

Iyer, Ramaswamy R (ed). Living Rivers, Dying Rivers. New Delhi: OUP. 2015.

Morton, Timothy. The Ecological Thought. Massachusetts (The USA): Harvard University Press. 2012.

Nayar K., Pramod. Contemporary Literary and Cultural Theory: From Structuralism to Ecocriticism. NOIDA: Pearson. 2010.

Srivasta, Asheem and Suvira Srivasta. Ecological Meltdown: Impact of Unchecked Human Growth on the Earth's Natural Systems. New Delhi: TERI. 2015.

Swamy, Subramanian. Hindutva and National Renaissance. New Delhi: Har-Anand Publications Pvt Ltd. 2010.

Waugh, Patricia (ed.). Literary Theory and Criticism: An Oxford Guide. New Delhi: Oxford University Press. 2006. 